\title{
Ebenaceae endémicas del Perú
}

\section{Blanca León ${ }^{1,2}$}

${ }^{1}$ Museo de Historia Natural, Av. Arenales 1256, Aptdo. 14-0434, Lima 14, Perú

2 Plant Resources Center, University of Texas at Austin, Austin TX 78712 EE.UU.

blanca.leon@mail.utexas.edu

\section{Resumen}

La familia Ebenaceae es reconocida en el Perú por presentar dos géneros y 16 especies (Brako \& Zarucchi, 1993; Ulloa Ulloa et al. 2004), todas ellas árboles. En este trabajo reconocemos seis endemismos en dos géneros. Diospyros es el que cuenta con el mayor número de especies endémicas. Estos taxones endémicos ocupan las regiones Bosques Húmedos Amazónicos y Bosques Montanos Muy Húmedos, entre los 120 y $1290 \mathrm{~m}$ de altitud. Cuatro de estos taxones endémicos se encuentran representados dentro del Sistema Nacional de Áreas Naturales Protegidas por el Estado.

Palabras claves: Ebenaceae, Diospyros, Perú, endemismo, plantas endémicas.

\section{Abstract}

The Ebenaceae are represented in Peru by 16 species in two genera (Brako \& Zarucchi, 1993; Ulloa Ulloa et al., 2004), all of them trees. Here we recognize six endemic taxa in two genera. Diospyros includes the largest number of endemic species. Endemic species are found in the Humid Lowland Amazonian Forests and Very Humid Montane Forests regions, between 120 and 1290 m elevation. Four endemic taxa have been registered to date in Peru's protected areas system.

Keywords: Ebenaceae, Diospyros, Peru, endemism, endemic plants.

\section{Diospyros manu B. Walln.}

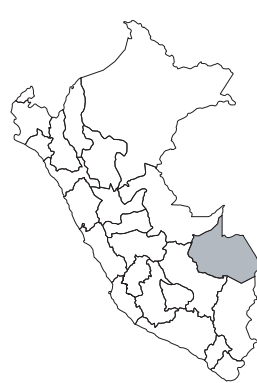

\section{VU, B1a}

Publicación: Ann. Naturhist. Mus. Wien, Ser. B, Bot. Zool. 101(B): 576-577. 1999. Colección tipo: A.H. Gentry 43708 Herbarios: FHO, MO, W.

Nombre común: Desconocido.

Registro departamental: MD.

Regiones Ecológicas: BHA; 200—550 m. SINANPE: PNM

Herbarios peruanos: USM (2).

Observaciones: Esta especie arbórea se conoce de unas pocas localidades, entre las cuencas de los ríos Tambopata y Madre de Dios; crece en suelos aluviales y aparentemente asociada a bosques no inundables.

\section{Diospyros panguana B. Walln.}

Publicación: Ann. Naturhist. Mus. Wien, Ser. B, Bot. Zool. 101(B): 583-584. 1999. Colección tipo: W. Morawetz \& B. Wallnöfer 18-27985

Herbarios: FHO, LZ, W; USM!.

Nombre común: Desconocido.

Registro departamental: HU, UC.

Regiones Ecológicas: BHA; 200—400 m. SINANPE: RCS

Herbarios peruanos: USM (isotipo).

Observaciones: Árbol bajo o arbusto, descrito de plantas recolectadas en la cuenca del Pachitea, en 1985. Esta especie es conocida también de la cuenca del Ucayali. La deforestación es probablemente la principal amenaza a sus poblaciones.

\section{Diospyros rotok B. Walln.}

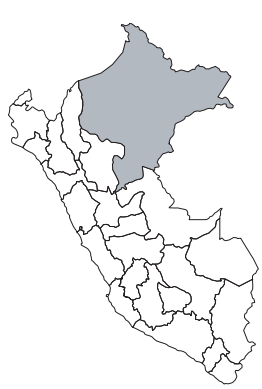

DD

Publicación: Ann. Naturhist. Mus. Wien, Ser. B, Bot. Zool. 101(B): 584—586. 1999. Colección tipo: L. Bernardi s.n. Herbarios: G.

Nombre común: Desconocido.

Registro departamental: LO.

Regiones Ecológicas: BHA; 120-125 m. SINANPE: Sin registro.

Herbarios peruanos: Ninguno.

Observaciones: Árbol descrito de una planta recolectada en 1976, de la cuenca del Ucayali. Todos los registros de esta especie provienen del Arboreto Jenaro Herrera.Se desconoce las condiciones de sus poblaciones fuera de esa localidad.

\section{Diospyros tessmannii Mildbr.}

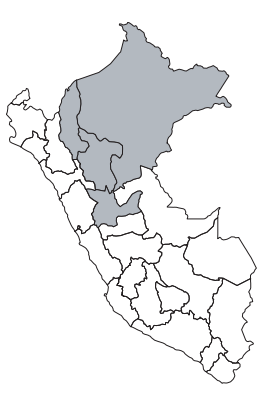

LC

Publicación: Notizbl. Bot. Gart. BerlinDahlem 10: 195. 1927.

Colección tipo: G. Tessmann 4635

Herbarios: B.

Nombre común: Desconocido.

Registro departamental: AM, HU, LO, SM.

Regiones Ecológicas: BHA; $160 \mathrm{~m}$.

SINANPE: RNAM, ZRSC

Herbarios peruanos: MOLF (1).

Observaciones: Arbusto, conocido de varias localidades dispersas en el noroccidente y centro de la Amazonía peruana. El ejemplar tipo fue recolectado en 1924 de la cuenca del Santiago, en el Departamento de Amazonas; esa localidad forma parte de la Zona Reservada Santiago-Comaina. 


\section{Diospyros urep B. Walln.}

DD

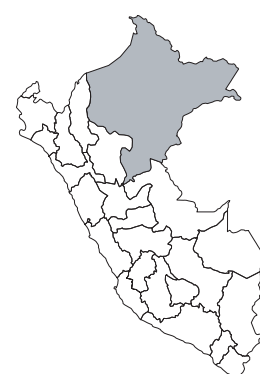

Publicación: Ann. Naturhist. Mus. Wien, Ser. B, Bot. Zool. 10(B): 587-589. 1999. Colección tipo: C. Díaz et al. 1281

Herbarios: FHO, MO.

Nombre común: Desconocido.

Registro departamental: LO.

Regiones Ecológicas: BHA; $132 \mathrm{~m}$.

SINANPE: Sin registro.

Herbarios peruanos: Ninguno.

Observaciones: Árbol descrito de una planta recolectada en la cuenca del Pastaza, en 1979, localidad en la que, al parecer, no ha vuelto a ser registrada. Se conoce también de la Provincia de Maynas.

\section{Lissocarpa uyat B. Walln.}

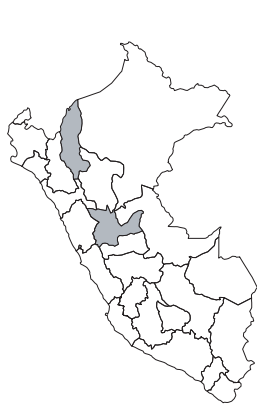

\section{LC}

Publicación: Ann. Naturhist. Mus. Wien, 105B: 557-560, f. 6g, 22-23. 2004.

Colección tipo: R. Vásquez et al. 21186 Herbarios: MO; HUT!, USM!.

Nombre común: Desconocido. Registro departamental: AM, HU.

Regiones Ecológicas: BMHP, BHA; $350-1290 \mathrm{~m}$.

SINANPE: RCS

Herbarios peruanos: HUT (isotipo), USM (isotipo+2).

Observaciones: Árbol, conocido principalmente de poblaciones en la cuenca del Imaza. Se conoce también de la cuenca del Pachitea, en la Reserva Comunal El Sira. Esta especie ha sido recolectada en el sotobosque de bosques sobre arenisca, con suelo cubierto por abundante materia orgánica. 